\title{
Introduction to 2018-I'
}

\section{Anders Buch}

\begin{abstract}
U
hat is the matter with contemporary working life? This question might indicate that something has gone astray in the way the labor market functions, or how it affects the wellbeing of working people. But the question might also be understood in a more profound sense: what really matters to people in working life? How do people (fail to) find meaning in the activities that they are involved in during work? What do people care about when working?
\end{abstract}

In his magnum opus Sein und Zeit (1927), the German philosopher Martin Heidegger famously identified our ability to care as an existential defining feature of the way we engage with the world and one another. He saw caring as an essential tenet that gives direction and installs purpose in the way we go about our businesses in our daily lives and the way we find ourselves at home in the world. We are 'concerned' about things - in the sense that we are oriented toward how things unfold in our lives. But our caring also often manifests itself as 'solicitude' - we care about the wellbeing of others.

This is also the case when we are engaged in work. Working life studies both investigate the functional dimensions of the labor market and the specificities of the unfolding of lived and experienced work. The four articles in this volume illustrate this nicely.

In the first article When Saving Time becomes Labor: Time, Work, and Technology in Homecare, Jenney M. Bergschöld asks how homecare workers describe their methods for saving time, and how the role of technology emerge in relation to these methods. She investigates the matter through an ethnographic field study of a homecare unit in Norway. Here, Bergschöld finds that the homecare workers self-identify as skillful timesavers, and that their time-saving work practices are closely related to the ICT-based app-technology they make use of in the homecare work. In fact, the ability to perform work in a short amount of time becomes a sign of professional competence. Bergschöld thus demonstrates how the introduction of the ICT-technology in significant ways affect the way that homeworkers care about their work.

In the second article of this issue Professional Bureaucracy and Healthcare Managers' Panned Change Strategies: Governance in Swedish Healthcare, by Jörgen Andreasson, Erik Ljungar, Linda Ahlstrom, Jonas Hermansson, and Lotta Dellve, the authors set out to investigate whether health care managers' approaches to coaching and appraisal of change and clinical autonomy is associated with health care process quality. Through interviews with managers at five hospitals in Sweden and questionnaires to employees working in units the managers were in charge of, the authors discuss how the coaching styles, appraisal of change, supporting organizational resources, the availability of an implementation strategy, and organizational autonomy of the clinics relates to health

\footnotetext{
${ }^{1}$ You can find this text and its DOI at https://tidsskrift.dk/njwls/index.
} 
care process quality (measured through the employees' responses in the questionnaire). The findings of the study indicate that the approaches of the managers (and their preconditions) have importance for the ability to implement change and stimulate health care process quality. One significant finding points out that managers who promote their own development ideas instead of just translating top management ideas are more successful in developing work. Maybe these managers care about the organization and work processes in different ways than the managers who just 'translate' top management ideas?

Åsmund Hermansen and Tove Midtsundstad investigate the effect of financial incentives for delaying early retirement in their article: The Effect of Retaining Bonuses on Delaying Early Retirement - Financial Incentives Revisited. The authors analyze the effect through a dataset of a Norwegian employer survey and register data on older employees in a 10-year period. The study not only detects a small retention effect of the financial incentives but also points to the complexity of the situations of the older employees where financial incentives are only one factor among many others in the work-retirement transition. The authors point to other studies that emphasize broadening the perspective to include other factors such as the prevention of health problems and reduced work capacity in retention strategies. Unsurprisingly, what older people care for in working life has a much broader spectrum than can be summoned by financial incentives.

The last article of this issue brings us into issues about labor migration in Sweden. Ole Frödin and Anders Kjellberg's article Labor migration from third countries to Swedish low-wage jobs discuss different explanations of why many third-country nationals were recruited to sectors of high unemployment and a large share of low-skilled jobs. The authors have studies work permits issued in the Stockholm restaurant and cleaning sectors in 2012 to labor migrants. One of the findings of the study suggests that there often exists a national/ethnic link between migrant and employers. Although this study is based on dossiers and register data, and no direct evidence of the motives of the migrant workers or employers is available, the authors reasonably suggest that employers of foreign origin wanted to help co-nationals to get a job in Sweden. Care in working life comes to the fore again.

This issue of the journal thus, once again, present accounts of the actual functioning of the Nordic labor market and the unfolding of working life as experienced activity. We learn about employers' and employees' concerns, worries, and how they eventually cope with working conditions. Working life matters to them. Thank you to all contributing authors of the issue for documenting and bringing forward these concerns. 